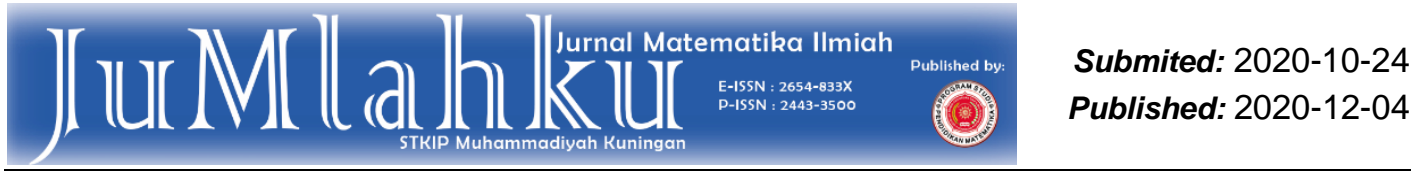

\title{
Pemanfaatan Aplikasi KAHOOT! Sebagai Media Pembelajaran Matematika Kreatif
}

M. Ardiansyaha)

a) Informatika, Fakultas Teknik dan IImu Komputer, Universitas Indraprasta PGRI m.ardiansyah_unindra@yahoo.co.id

$\frac{\text { Article Info }}{\text { Kaywords : Industrial }}$
revolution 4.0, KAHOOT!,
Qualitative

Abstract
Effective, conducive and certainly fun learning in era of industrial
revolution 4.0 makes changes in learning styles and processes.
Educators be able to follow the development of science and
technology by following the interactive digital learning process,
especially mathematics. Learning is fun and not monotonous is one
of the biggest challenges for technology managers and developers
how to find make the learning process better and of course have to
innovate a lot. Interactive learning innovation in this research is to
use the KAHOOT! interactive learning media based on games which
focuses on the active participation learning style of all students. One
of the KAHOOT applications! used is the use of online quizzes, where
learners directly reflect their answers online and KAHOOT! record all
activities of students that can be material for an assessment resume
for educators. This study aims to determine the feasibility of
implementing KAHOOT! in the learning process by understanding
students' responses to this application. This study uses a qualitative
method using KAHOOT! on learning mathematics to 30 students
class X of the SMK Islam Perti, West Jakarta. This study obtained a
final percentage of 90\% with very attractive criteria. So it can be
concluded that the use of the KAHOOT! which is used is very suitable
in creating creative and fun learning.


Kata Kunci: Revolusi industri 4.0, KAHOOT, Kualitatif

\begin{abstract}
Abstrak
Pembelajaran yang efektif, kondusif dan tentunya Kreatif di era revolusi industri 4.0 membuat perubahan dalam gaya dan proses pembelajaran. Pendidik harus dapat mengikuti perkembangan IPTEK dengan cara mengikuti proses pembelajaran digital interaktif khususnya matematika. Pembelajaran yang Kreatif dan tidak monoton menjadi salah satu tantangan terbesar bagi pengelola dan pengembang teknologi bagaimana menemukan cara agar proses pembelajaran bisa menjadi lebih baik dan tentunya harus banyak berinovasi. Inovasi pembelajaran interaktif dalam penelitian ini adalah dengan menggunakan aplikasi KAHOOT! sebagai media pembelajaran interaktif berbasis games yang menitikberatkan pada gaya belajar partisipasi aktif semua peserta didik. Salah satu aplikasi KAHOOT! yang digunakan adalah penggunaan kuis online, dimana peserta didik secara langsung merefleksikan jawaban mereka secara online dan KAHOOT! mencatat semua aktivitas peserta didik yang dapat menjadi bahan resume penilaian bagi pendidik. Penelitian ini bertujuan untuk mengetahui kelayakan penerapan KAHOOT! dalam proses pembelajaran dengan memahami tanggapan peserta didik terhadap aplikasi ini. Penelitian ini menggunakan metode Kualitatif dengan menggunakan KAHOOT! pada pembelajaran matematika terhadap 30 peserta didik yang berada di kelas X SMK Islam Perti Jakarta Barat. Penelitian ini memperoleh persentase akhir sebesar $90 \%$ dengan kriteria Sangat Menarik. Sehingga dapat disimpulkan bahwa penggunaan aplikasi KAHOOT! yang digunakan sangat sesuai dalam menciptakan pembelajaran yang kreatif dan menyenangkan.
\end{abstract}

\section{PENDAHULUAN}

Teknik pembelajaran ekspositori cenderung membuat pelajaran matematika membosankan karena suasana proses pembelajaran di kelas tidak menarik dan cenderung peserta didik cukup sulit untuk fokus dan mencerna pembelajaran. Kebanyakan mencatat dan tidak pernah menerangkan materi yang diajarkan berakibat proses pembelajaran dan pengajaran menjadi tidak kondusif, menarik, dan membosankan bagi peserta didik. Sehingga di dalam dunia pendidikan sangat dibutuhkan sebuah media pembelajaran agar tujuan yang diharapkan 146 tercapai. Di Era Revolusi Industri 4.0 yang tengah melanda segi kehidupan membuat sekolah harus mampu menyesuaikan dengan perkembangan ilmu dan teknologi, salah satunya menjadikannya dalam proses pembelajaran yang kondusif dan Kreatif. Pendidik memiliki peran penting dalam hal mengembangkan inovasi, ide atau gagasan untuk pemanfaatan teknologi dalam pembelajaran.

Konsep dalam penelitian ini mengacu pada games yang merupakan suatu teknik pembelajaran di kelas yang berorientasi pada permainan kelompok yang dapat membantu meningkatkan 
kualitas dan potensi peserta didik dalam menyerap pelajaran matematika khususnya. (Dellos, 2015) menyatakan bahwa pembelajaran berlandasan permainan merupakan alat yang dapat membantu peserta didik dalam menyelesaikan masalah, meningkatkan pemikiran kritis dan membuat sebuah penilaian dalam proses pembelajaran. sedangkan menurut Huang (2011) menyatakan penelitian di bidang pendidikan menunjukkan bahwa pembelajaran berbasis games adalah salah satu alat yang efektif dalam pengajaran terutama untuk meningkatkan dan menjaga motivasi dalam kelanjutan pembelajaran.

Secara umum permainan itu dalam kenyataannya sangat Kreatif dan memberikan motivasi dalam pembelajaran. Banyak literatur menyatakan bahwa pembelajaran yang bersifat ke arah permainan yang melibatkan partisipasi dari peserta didik dalam pembelajaran matematika melalui teknologi digital, menunjukkan adanya keingingan yang lebih besar dalam melanjutkan proses pembelajaran yang berikutnya dibandingkan dengan pembelajaran bersifat konvensional. (Sutirna, 2018) Permainan edukatif dan transformatif merupakan sebuah permainan yang digunakan dalam proses pembelajaran dan dalam permainan itu mengandung unsur dan nilai pendidikan.

Di era revolusi 4.0 ini untuk menciptakan inovasi pembelajaran matematika yang unik dan Kreatif tentunya membutuhkan sarana teknologi sebagai penyambung interaksi dalam proses pembelajaran. Hal ini senada dengan pendapat (Nurseto, 2011) bahwa pemanfaatan media teknologi sebagai sarana pembelajaran adalah mempermudah peserta didk maupun pengajar dalam mengelola, menyampaikan pengajaran serta menjadikan pengalaman belajar yang menarik. Pemanfaatan media dalam pembelajaran dapat membangkitkan keinginan, minat dan bakat baru, meningkatkan semangat dalam proses pembelajaran di sekolah, dan sangat berpengaruh secara moral kepada peserta didik.

Salah satu model inovasi yang dapat dikembangkan agar proses pembelajaran menjadi kondusif, interaktif, menarik serta dapat membantu pengajar membuat evaluasi penilaian terhadap peserta didik adalah dengan menggunakan aplikasi KAHOOT!. KAHOOT! dapat mempermudah pendidik dalam mengevaluasi (Kurnia, 2018). KAHOOT! merupakan salah satu pilihan dari banyak macam media pembelajaran yang dapat menjadikan pembelajaran di sekolah bisa menjadi Kreatif dan tidak membosankan peserta didik maupun pengajar karena pada dasarnya aplikasi KAHOOT! membuat gaya dalam belajar menitikberatkan peran aktif dalam partisipasi peserta didik dengan sejawatnya dalam hal persaingan mendapatkan nilai terbaik dalam pembelajaran yang telah dipelajarinya (Nor \& Ahmad, 2017). KAHOOT! dapat mempengaruhi dalam hal perkembangan mental, sosial, dan emosi peserta didik dalam mengembangkan berkompetisi dan berkolaborasi dengan sejawatnya.

KAHOOT! adalah laman web yang bersifat edukatif yang mulanya ditemukan 
oleh Johan Brand, Jamie Brookerdan Morten Versvik disebuah joint project dengan Norwegian University of Technology and Science pada maret 2013. Kahoot dibuka secara publik pada bulan September 2013 (Official Website 'Kahoot!", 2017). Hingga saat ini telah 70 juta lebih user aktif yang menggunakan Kahoot dan 1,6 milyar peserta didik untuk memainkan permainan ini.

Permainan secara berkelompok merupakan desain paling utama dari penggunaan KAHOOT! selain juga dapat dimainkan secara perorangan. Adapun alamat website Kahoot yaitu https://kahoot.com/ untuk pengajar dan https://kahoot.it/ untuk peserta didik. Penggunaan. Quis online, survey, diskusi dan campuran adalah platform Kahoot yang dapat dimanfaatkan, dimana untuk memainkannya ada cara yang beragam. Pembelajaran dengan menggunakan Aplikasi Kahoot juga membutuhkan sambungan jaringan internet. (Arsyad, 2013) mengemukakan pembelajaran dengan komputer mampu merangsang peserta didik untuk mengerjakan berbagai latihan dikarenakan tersedianya berbagai animasi, ilustrasi grafik, dan warna yang menambah kreativitas peserta didik.

Permainan KAHOOT! dalam penelitian ini adalah memanfaatkan aplikasi kuis online. Pembelajaran di kelas dengan aplikasi KAHOOT! dilaksanakan dengan cara sebagai berikut : (1) pendidik membuat akun secara gratis dan masuk ke website https://kahoot.com/ yang nantinya juga dapat dihubungkan pada akun google (2) Pendidik dapat membuat materi soal yang sudah dipersiapkan sesuai kebutuhan pembelajaran peserta didik. (3) Setelah materi selesai dibuat, pendidik memberikan pin akses yang diberikan oleh KAHOOT! dan meminta peserta didik mengakses website https://kahoot.it untuk memasukakan pin serta username (untuk lebih memudahkan, pendidik dapat menggunakan infocus. (4) Perangkat utama pendidik akan menampilkan pertanyaan yang kita buat yang berupa pilihan ganda atau pernyataan salah atau benar

Peserta didik memilih jawaban yang sesuai dari perangkat yang ada sesuai dengan durasi waktu yang telah ditentukan pendidik. (6) Peserta didik yang memilih menjawab paling cepat dan tepat tentunya akan mendapatkan skor yang lebih tinggi. (7) Diakhir permainan nantinya pendidik dapat menyimpan hasil skor dan jawaban dari peserta didik di google drive atau langsung di download pada laptop dalam bentuk spreetsheet, sebagai bahan evaluasi sebagai penilaian, agar lebih menyenagkan pendidik dapat memberikan hadiah ke peserta didik yang mendapatkan skor tertinggi dari yang lainnya.

\section{METODE}

Tujuan utama penelitian ini adalah untuk mendapatkan gambaran tentang bagaimana suatu keadaan peserta didik sehingga di desain sebagai salah satu solusi pemecahan masalah yang di hadapi terhadap kondisi yang dihadapi peserta didik. Adapun maksud dari penelitian ini adalah untuk memberikan penjelasan tentang pemahaman perseorangan, maupun kelompok secara akurat dalam penggunaan aplikasi KAHOOT! sebagai media pembelajaran interaktif.

Sesuai dengan tujuan dan maksud dari penelitian ini, maka metode penelitian 
yang digunakan adalah penelitian kualitatif dengan melakukan pemberian kuis langsung dengan aplikasi KAHOOT! pada Sekolah Menegah Kejuruan Islam Perti Jakarta Barat. Pada akhir pelaksanaan penelitian kepada peserta didik akan dimintakan pendapatnya dengan cara wawancara kepada peserta didik terhadap penggunaan KAHOOT! terhadap pembelajaran matematika yang diberikan. Adapun jumlah peserta didik yang berpartisipasi dalam kegiatan ini adalah sebanyak 30 orang.

\section{HASIL DAN PEMBAHASAN}

\section{Tampilan halaman utama KAHOOT!}

Halaman utama merupakan halaman yang muncul pertama kali saat pengunjung mengakses website Kahoot.com

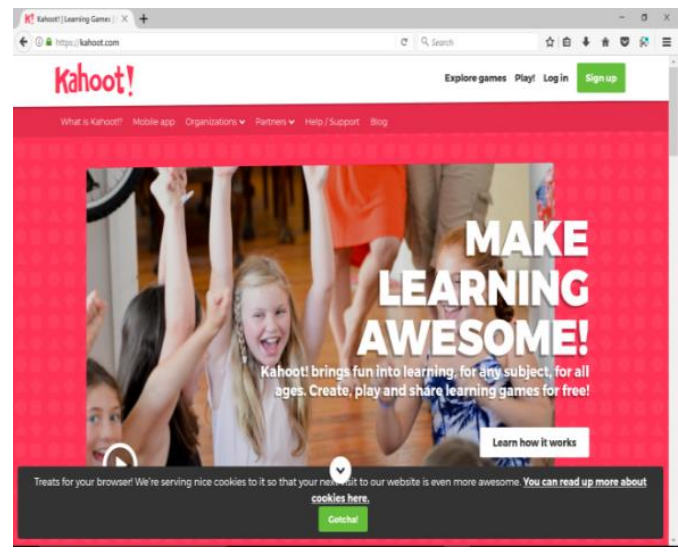

Gambar 1. tampilan utama KAHOOT!
Menu KAHOOT!

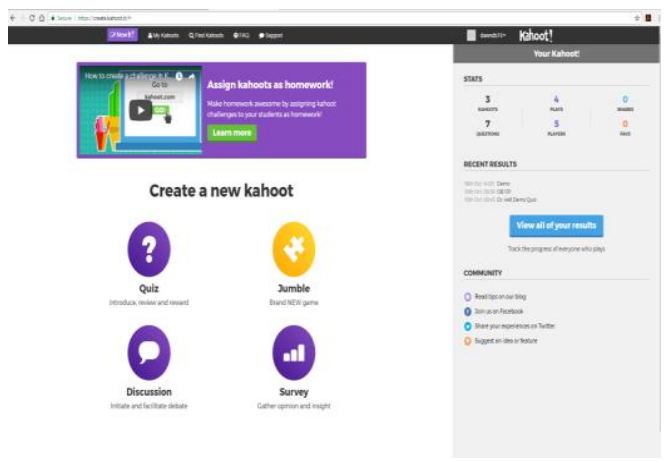

Gambar 2. Menu KAHOOT!

Tampilan pada saat membuat Kuis Pada saat mau menginput soal ke aplikasi KAHOOT!

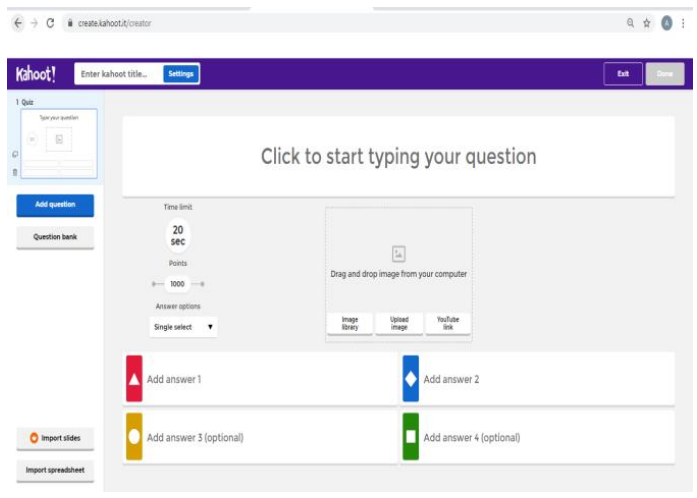

Gambar 3 Tampilan awal pembuatan soal kuis untuk peserta didik 
Penginputan Soal matematika

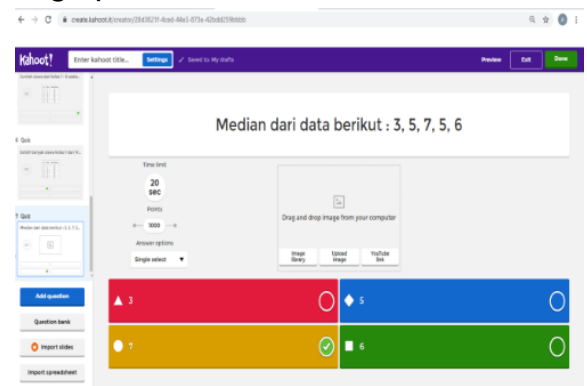

Gambar 4 soal matematika

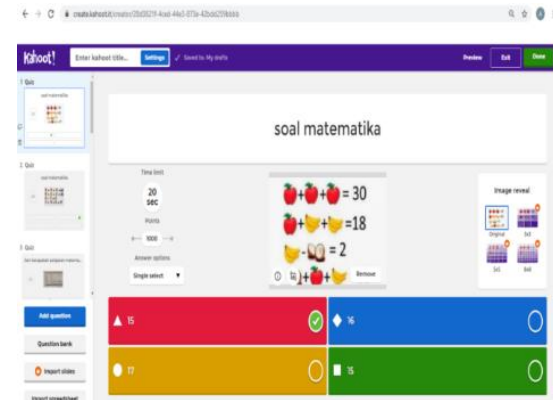

Gambar 5 games atau Kuis Matematika

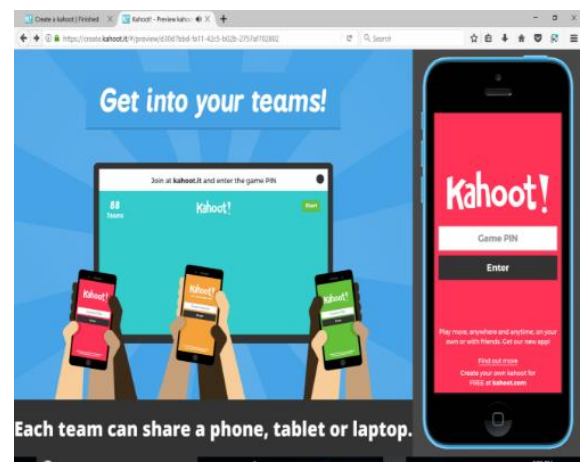

Gambar 6 Tampilan Kahoot! Di Handphone peserta didik

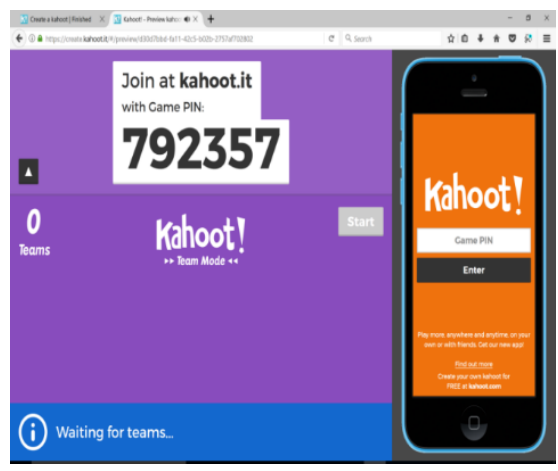

Gambar 7 PIN Kahoot siswa

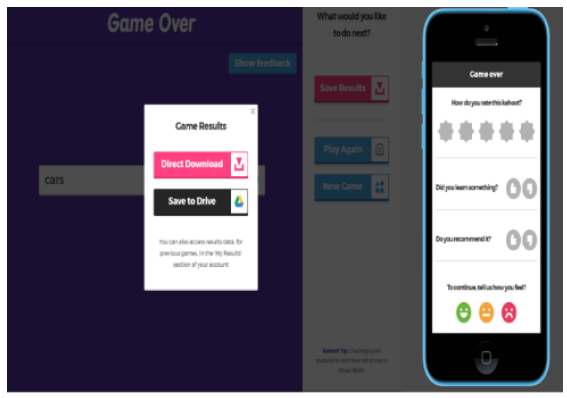

Gambar 8 Penyimpanan file Pendidik

\section{HASIL PENELITIAN}

Adapun hasil penelitian ini adalah didasarkan pada variabel pendapat dari peserta didik tentang aplikasi KAHOOT! kuis yang terdiri dari indikator kualitas isi pokok pembahasan, bahasa yang digunakan dan kemudahan. Hasil persepsi wawancara penilaian peserta didik dalam penggunaan aplikasi Kahoot sebagai media pembelajaran kreatif atas 25 pernyataan dengan 5 pilihan jawaban, yaitu 
Sangat Tidak Setuju (STS) dengan skor 1, Tidak Setuju (TS) skor 2, Kurang Setuju (KS) skor 3, S (Setuju) skor 4 dan Sangat Setuju (SS) skor 5 . Adapun pernyataan dan skor pilihan jawabannya adalah :

- Tampilan aplikasi KAHOOT! pada kuis matematika ini menarik, $S$ mendapatkan skor 40 dan 75 mendapatkan skor SS.

- Lebih semangat untuk belajar dengan adanya Kuis matematika dengan aplikasi KAHOOT!, S mendapatkan skore 32 dan SS mendaptkan skore 85.

- Penggunaan aplikasi KAHOOT! ini membuat pembelajaran matematika menjadi lebih menarik dan tidak membosankan, mendapatkan skor 20 untuk pilihan jawaban S, 100 untuk pilihan jawaban SS.

- Aplikasi KAHOOT! kuis ini sangat jauh lebih baik dibandingkan pengajaran konvensional baik dari segi tampilan visual (foto, gambar, dll), mendapatkan 12 untuk pilihan jawaban S dan 110 untuk pilihan jawaban SS.

- Motivasi belajar peserta didik meningkat dengan adanya penerapan aplikasi KAHOOT!, mendapatkan skor 40 untuk pilihan jawaban $S$ dan 75 untuk pilihan jawaban SS.

- Penggunaan aplikasi KAHOOT! dapat membuat peserta didik tertarik untuk mengikuti kuis, mendapatkan skor 28 untuk pilihan jawaban $S$ dan 90 untuk pilihan jawaban SS.

- Pemberian Kuis menggunakan aplikasi KAHOOT! kurang bermanfaat bagi peserta didik dalam Pembelajaran matematika, mendapatkan skor 30 untuk pilihan jawaban KS, 40 untuk pilihan jawaban $S$ dan 20 untuk pilihan jawaban SS.

- Peserta didik lebih suka mengerjakan soal kuis menggunakan aplikasi KAHOOT!, mendapatkan skor 48 untuk pilihan jawaban $S$ dan 65 untuk pilihan jawaban SS.

- Soal dalam kuis yang disajikan di aplikasi KAHOOT! membuat peserta didik lebih sulit memahami soal, mendapatkan skore 16 untuk pilihan jawaban TS, 15 pilihan jawaban KS, 36 pilihan $S$ dan 15 untuk pilihan jawaban SS.

- Aplikasi KAHOOT! memudahkan peserta didik mengerjakan dan memahami soal kuis matematika, mendapatkan skor 9 untuk pilihan jawaban KS, 60 pilihan S dan 35 untuk pilihan jawaban SS.

- Materi soal yang disajikan mudah dipahami, mendapatkan skor 15 untuk pilihan jawaban KS, 44 pilihan $S$ dan 45 untuk pilihan jawaban SS.

- Pada saat ujian pengambilan nilai, sangat memudahkan pendidik dengan adanya aplikasi KAHOOT!, mendapatkan skor 6 untuk pilihan jawaban KS, 48 pilihan S dan 50 untuk pilihan jawaban SS.

- Mudah mengakses aplikasi KAHOOT!, mendapatkan skor 32 untuk pilihan jawaban $S$ dan 85 untuk pilihan jawaban SS.

- Kemudahan dalam menggunakan aplikasi KAHOOT! ini, mendapatkan skor 52 untuk pilihan jawaban $S$ dan 60 untuk pilihan jawaban SS. 
- Kemudahan untuk dimengerti, baik dari segi menu maupun fasilitas (tombol), mendapatkan skor 12 untuk pilihan jawaban KS, 44 untuk pilihan S dan 50 untuk pilihan jawaban SS

- Kejelasan dan kemudahan pemahaman kalimat yang digunakan dalam soal, mendapatkan skore 24 untuk pilihan jawaban KS, 48 untuk pilihan $S$ dan 25 untuk pilihan jawaban SS.

- Bahasa yang digunakan dalam kuis matematika ini cukup sederhana dan mudah dimengerti, mendapatkan skor 28 untuk pilihan jawaban $S$ dan 75 untuk pilihan jawaban SS.

- Simbol yang digunakan pada kuis matematika cukup sederhana dan mudah di telaah, mendapatkan skor 60 untuk pilihan jawaban $S$ dan 50 untuk pilihan jawaban SS.

- Materi soal yang disajikan mudah dipahami, mendapatkan skor 18 untuk pilihan jawaban KS, 48 pilihan S dan 35 untuk pilihan jawaban SS.

- Tes evaluasi dapat menguji seberapa jauh pemahaman tentang materi yang sudah diajarkan di kelas lewat Kuis menggunakan aplikasi KAHOOT!, mendapatkan skore 6 untuk pilihan jawaban KS, 68 untuk pilihan S dan 30 untuk pilihan jawaban SS.

\section{PEMBAHASAN HASIL PENELITIAN}

Berdasarkan dari persepsi dan hasil persentase penilaian peserta didik terhadap penggunaan aplikasi KAHOOT! dapat dilihat bahwa indikator minat belajar peserta didik sebesar $91 \%$ dengan kriteria "Sangat Menarik", yang berarti bahwa peserta didik sangat tertarik untuk 152 menggunakan aplikasi KAHOOT! sebagai kuis dalam pembelajarannya. Luqman (2017) Pembelajaran yang sangat Kreatif, menarik minat dan tidak membosankan peserta didik, adalah salah satu awal agar pembelajaran di sekolah menjadi bermakna dan berguna bagi peserta didik. conclusion that students' motivation, engagement, and learning outcomes can be enhanced through game-based response systems, citing Kahoot! as a case in point (Benhadj et al., 2019). Sedangkan Arsyad (2013) mengatakan suasana proses pembelajaran yang Kreatif bagi peserta didik akan memusatkan perhatian peserta didik secara penuh pada proses pembelajaran sehingga dapat meningkatkan kualitas dan semangat belajar pesrta didik.

Indikator kemudahan dari penggunaan KAHOOT! oleh peserta didik sebesar 90\% dengan kriteria "Sangat Menarik", yang berarti peserta didik sangat mudah dalam penggunaan aplikasi KAHOOT! sebagai kuis dalam pembelajaran di kelas. Dalam perkembangan teknologi 4.0 yang cepat menjadi bernilai, jika salah satunya mudah dalam penggunaannya. These challenges were the difficulties in reaching the Kahoot! website, the problems about the internet connection, the difficulties in reading the board, the difficulties in selecting the answers and the application's disconnections because of the connection timeouts. The teacher, however, displayed positive opinions about the Kahoot! Application (Sibel Çetin, 2018).

Indikator keabsahan sebesar $90 \%$ dengan kriteria "Sangat Menarik", berarti peserta didik dapat mengerti dan jelas 
pemaparan soal kuis yang akan ditampilkan lewat aplikasi KAHOOT! dalam pelajaran matematika, meskipun dalam pembuatan soal maupun jawaban kuis pada aplikasi KAHOOT! tatanan jumlah hurufnya cukup terbatas. Dalam penelitian ini KAHOOT! sebagai media pembelajaran yang tepat dapat menyalurkan bahan pembelajaran yang dapat mudah dimengerti oleh peserta didik.

Indikator kualitas isi sebesar 91\% dengan kriteria "Sangat Menarik", berarti peserta didik tetap menyatakan kualitas soal menarik dan mudah dipahami yang diberikan oleh pendidik dalam matapelajaran matematika dengan menggunakan aplikasi KAHOOT!, sehingga kompetensi rencana pembelajaran terpenuhi. Pemanfaatan teknologi informasi untuk meningkatkan kualitas proses pendidikan antara lain meliputi managemen system informasi (SIM), e-learning, media pembelajaran, dan pendidikan life skill. Penggunaan KAHOOT! sebagai media pembelajaran dapat meningkatkan kualitas isi pembelajaran.

Dari keempat indikator penilaian ini secara rata-rata persepsi peserta didik dengan penggunaan platform kuis KAHOOT! sebagai media pembelajaran sebesar 90\% yang berarti "Sangat Menarik" untuk diaplikasikan dan digunakan dalam kelas, sehingga permasalahan kebosanan, ketidaktertarikan dalam belajar dan dilema pengajar menyongsong era revolusi 4.0 dapat menggunakan KAHOOT! sebagai media pembelajaran tanpa mengurangi tujuan, konten dan isi kualitas pembelajaran. Hal ini sesuai dengan penelitian dari Irwan et al (2019) "The results shows that Kahoot can be an alternative interactive learning media in higher education because it is proven to significantly improve student learning outcomes. Selain itu, (Irwan \& Waldi, 2019) Kahoot! efektif dalam sebagai media pembelajaran dalam menunjang proses belajar dan mengajar. In conclusion, the gamification method has an impact on students that renders them more ambitious and motivated to study (Bicen \& Kocakoyun, 2018). Penggunakan aplikasi kahoot sangat layak digunakan untuk meningkatkan pembelajaran matematika peserta didik (Sartika \& Octafiani, 2019).

\section{PENUTUP \\ Simpulan}

Dari pemaparan di atas maka dapat disimpulkan: 1) Penggunaan aplikasi KAHOOT! sebagai media pembelajaran mudah di pahami, sangat menarik, dan Kreatif dipergunakan dalam proses pembelajaran di sekolah. 2) Penggunaan aplikasi KAHOOT! dapat meningkatkan semangat belajar peserta didik. 3) Aplikasi KAHOOT! kuis sebagai inovasi dalam pembelajaran dapat meningkatkan kualitas keaktifan peserta didik dalam proses pembelajaran di kelas maupun online. 4) Pengembangan media pembelajaran tentang teknologi pembelajaran diperlukan keuletan dan kreatifitas dalam menciptakan inovasi teknologi dalam pembelajaran di kelas maupun online.

\section{Saran}

Berdasarkan hasil penelitian ini, dapat disarankan beberapa hal kepada: 1) Guru diharapkan lebih kreatif dalam memilih media pembelajaran sehingga dapat 
meningkatkan hasil belajar matematika siswa. 2) Kepala sekolah diharapkan lebih memberikan kesempatan kepada guru untuk mengembangkan kompetensi yang dimilikinya dan menyediakan sarana serta prasarana untuk dapat menggunakan media pembelajaran Kahoot. 3) Peneliti sejenis kiranya dapat menggunakan hasil penelitian ini sebagai bahan rujukan atau referensi untuk mengembangkan media pembelajaran sehingga mampu mengatasi permasalahan dalam pembelajaran matematika.

\section{DAFTAR PUSTAKA}

Azhar Arsyad. (2013). Media Pembelajaran. PT. RajaGrafindo Persada.

Benhadj, Y., Messaoudi, M. El, \& Nfissi, A. (2019). Investigating the Impact of Kahoot! on Student s ' Engagement , Motivation , and Learning Outcomes: Ifrane Directorate as a case study. International Journal of Advance Study and Research Work.

Bicen, H., \& Kocakoyun, S. (2018). Perceptions of students for gamification approach: Kahoot as a case study. International Journal of Emerging Technologies in Learning. https://doi.org/10.3991/ijet.v13i02.74 67

Dewi, Kurnia, C. (2018). Pengembangan Alat Evaluasi Menggunakan Aplikasi Kahoot pada Pembelajaran Matematika Kelas $X$. Raden Intan.

Harlina, Nor, Z. M., \& Ahmad, A. (2017). Pembelajaran Interaktif Berasaskan Aplikasi Kahoot dalam Pengajaran Abad Ke-21. Seminar Serantau, 627635.
Huang, W. H. (2011). Evaluating learners' motivational and cognitive processing in an online game-based learning environment. Computers in Human Behavior. 694-704.

Irwan, I., Luthfi, Z. F., \& Waldi, A. (2019). Efektifitas Penggunaan Kahoot! untuk Meningkatkan Hasil Belajar Siswa [Effectiveness of Using Kahoot! to Improve Student Learning Outcomes]. PEDAGOGIA: Jurnal Pendidikan.

https://doi.org/10.21070/pedagogia.v $8 \mathrm{i} 1.1866$

Irwan, I., \& Waldi, A. (2019). Implementasi Kahoot! sebagai Inovasi Pembelajaran. Journal of Civic Education.

https://doi.org/10.24036/jce.v2i1.130

Luqman, M., Hakim, I., Saad, M., Teknologi, U., Zulfadhli, A., Universiti, N., Mara, T., Ahamad, M., Teknologi, U., Bahasa, K., View, A., Kahoot, A., Luqman, M., Hakim, I., \& Saad, M. (2017). Penggunaan Aplikasi Kahoot ! Dalam Pembelajaran Bahasa Arab: Satu Tinjauan. Sembara 2017, October.

Official Website 'Kahoot!". (2017). kahoot.com/company/. 23 September 2018.

Ryan Dellos. (2015). Kahoot! A digital game resource for learning. In International Journal of Instructional Technology and Distance Learning Vol 12 (pp. 49-52).

Sartika, \& Octafiani, M. (2019). Pemanfaatan Kahoot Untuk Pembelajaran Matematika Siswa Kelas X Pada Materi Sistem Persamaan Linear Dua Variabel. 
Journal On Education.

Sibel ÇETIN, H. (2018). Implementation of the Digital Assessment Tool "Kahoot!" in Elementary School. International Technology and Education Journal.

Sutirna. (2018). Seminar Nasional Semnas Ristek. Peran Teknologi Informasi Dalam Mendukung Stabilitas Nasional, 269-276.

Tejo Nurseto. (2011). Membuat Media Pembelajaran yang Menarik. Ekonomi Dan Pendidikan, Volume 8 N, 19-35. 